\title{
Modelling of climate change impact on flow conditions in the lowland anastomosing river
}

\author{
Paweł Marcinkowski ${ }^{\text {Corresp., }}{ }^{\text {, Dorota Mirosław-Świątek }}{ }^{1}$ \\ ${ }^{1}$ Department of Hydrology, Meteorology and Water Management, Warsaw University of Life Sciences - SGGW, Warsaw, Poland \\ Corresponding Author: Paweł Marcinkowski \\ Email address: p.marcinkowski@levis.sggw.pl
}

Progressive degradation of freshwater ecosystems worldwide forces actions for their conservation. Nowadays protection strategies need to step beyond the traditional approach of management of protected areas, as they have to deal with protection or recovery of natural flow regimes, disrupted by effects of future climate conditions. Climate change affects the hydrosphere at catchment scale altering hydrological processes which in turn impact hydrodynamics at the river reach scale. Therefore, conservation strategies should consider mathematical models, which allow for an improved understanding of ecosystem functions and their interactions across different spatial and temporal scales. This study focuses on an anastomosing river system in north-eastern Poland, where in recent decades significant loss of the anabranches has been observed. The objective was to assess the impact of projected climate change on average flow conditions in the anastomosing section of the River Narew. The Soil and Water Assessment Tool (SWAT software) for the Narew catchment was coupled with the HEC-RAS one-dimensional unsteady flow model. The study looked into projected changes for two future time horizons 2021-2050 and 2071-2100 under the Representative Concentration Pathway 4.5, using an ensemble of nine EURO-CORDEX model scenarios. Results show that low flow conditions in the anastomosing section of the Narew National Park will remain relatively stable in 2021-2050 compared to current conditions and will slightly increase in 2071-2100. Duration of low flows, although projected to decrease on an annual basis, will increase for August-October, when the loss on anastomoses was found to be the most intense. Hydraulic modelling indicated extremely low flow velocities in the anastomosing arm $(<0.1$ $\mathrm{m} / \mathrm{s}$ ) nowadays and under future projections which is preferable for in-stream vegetation development and their gradual sedimentation and closure. 
1 1. Introduction

2 Climate change is considered to be one of the greatest challenges nowadays and preventing it is a

3 key strategic priority for the European Union. It is expected that it will amplify current pressures

4 on natural resources, but also create new ones (IPCC, 2014). Riverine ecosystems, which provide

5 a diverse range of services, upon which humans are dependent, are listed amongst the most

6 sensitive to climate change of all ecosystems (Ormerod, 2009). Thus, it is obvious that effective

7 water management is crucial to successful climate change adaption (Ostfeld et al., 2012).

8 Climate change affects riverine ecosystems directly, by determining hydrological processes

9 (where precipitation, temperature and evaporation are the key drivers), and indirectly, by

10 changing the human use of river catchments, riparian zones and floodplains (IPCC, 2014; Ormerod, 2009). In the face of progressive degradation of riverine ecosystems worldwide (Millennium Ecosystem Assessment, 2005), communities and governments are forced to consider strategies for conservation management. Such strategies need to step beyond the traditional approach of management of protected areas, as they have to deal with protection or recovery of natural flow regimes, disrupted by effects of future climate change, which is considerably uncertain (Kingsford, 2011).

Conservation strategies and particular measures preventing from further decline in the health of aquatic ecosystems should consider mathematical models, which allow understanding of ecosystem functions and their interactions across different spatial and temporal scales (Jähnig et al. 2012). Catchment-scale hydrological changes driven by climate change strongly impact conditions at finer scales i.e. in-stream hydraulics in river reaches (Kiesel et al., 2013). Attempts to model the impact of climate change on water resources at watershed scale have been conducted extensively (Giri et al., 2019; Napoli et al., 2017; Krysanova et al. 2016; Kundzewicz et al., 2018, Kharel and Kirilenko, 2018, Tamm et al., 2018), however, such large scale models still lack of components that allow to downscale catchment-scale hydrological processes outputs to in-stream hydraulics. Therefore, an Integrated Modelling Framework (IMF) has been proposed by Jähnig et al. (2012) aimed at providing the environmental data and describing highly complex interactions between atmosphere, hydrosphere and biosphere across different spatial scales. So far, such IMF approach has been successfully applied in numerous studies: Guse et al. (2015) simulated land use and climate change impact on hydraulics and habitat 
31 suitability for fish and macroinvertebrates; Kail et al. (2015) assessed the effect of different

32 pressures on abiotic habitat conditions and the biota of rivers; Visser et al. (2019) proposed a coupled hydrological and hydroecological modelling framework to assess the impact of climate change on hydroecological response. The scope of the presented studies (Guse et al., 2015; Kail et al., 2015; Visser et al., 2019) demonstrates the open-ended character of IMF which allows tackling diverse region and site-specific problems concerning riverine ecosystems.

One of the examples of such issues described by Lewin et al. (2010) and Walter and Merritts (2008) is the loss of multichannel anastomosing rivers from most of temperate lowland floodplains because of direct and indirect human activities. Once very common, now they are rare in the developed world, which forces their conservation even more. Most of the studies concerning the origin and evolution of anastomosing rivers were qualitative in nature (Kleinhans et al., 2012; Makaske et al., 2017), and thus, more quantitative and model-based assessment is required. Previous studies on modelling the multi-channel river systems mostly concentrated on vegetation-flow interactions (Schuurman et al., 2013; Marcinkowski et al., 2018b) and sediment transport (Nicholas et al., 2013). However, none of the studies investigated the impact of climate change on flow conditions, by means of hydrological modelling, which is crucial in the light of long-term conservation programs for riverine ecosystems protection.

Anastomosing rivers extinction has been reported widely and is a common issue around the world (Lewin et al., 2010; Walter and Merritts, 2008). Their conservation is challenging due to multiple anthropogenic and natural stressors. In this study we use the example of the anastomosing river system in north-eastern Poland, to describe the potential impact of climate change on river flow characteristics and recommendations for conservation plans. In the anastomosing Narew in recent decades significant loss of the anabranches has been observed (Marcinkowski et al. 2018a). The mechanisms controlling the loss were reported by Marcinkowski et al. (2017a) and attributed mainly to changes in flow conditions, determined by different factors at catchment and reach scale. In the strictest sense, they observed that low water levels in anabranches facilitated sediment deposition and the colonization of common reed, while reduced high flows minimized sediment mobilization. Encroaching vegetation reduced flow efficiency and channel capacity, which in turn created perfect conditions for river bed aggradation and further reed colonization. After a few years, the former anabranch was 
61 eventually overgrown by reeds and disappeared completely. Therefore, as indicated by Marcinkowski et al. (2017a) low flow conditions are of special concern due to the fact that anabranches loss is recognized to be most intense during the summer season. In another study Marcinkowski et al. (2019) conducted an ex-ante model-based assessment of conservation measures efficiency, proposed in the protection plan (Mioduszewski et al. 2014) of the anastomosing section of the river in the Narew National Park (NNP). In the protection plan following conservation measures were proposed: (1) mowing of in-stream vegetation, (2) dredging of anabranches and (3) placement of submerged wooden weirs at the main channel redirecting part of the flow into anabranch. Marcinkowski et al. (2019) indicated that the only way to maintain the anastomosing character of the river requires highly invasive engineering solutions (channel dredging and building water dams). However, before any implementation of engineering solutions, which might cause serious ecological consequences in the protected area, a look ahead into potential flow changes caused by climate change projections is required. It might turn out that predicted increased precipitation in this part of Europe (Jacob et al., 2014), could potentially reverse the anastomosing system degradation, by increasing low flows in anabranches - the main factor responsible for channel extinction. Or contrarily, it might turn out that higher evapotranspiration rates due to temperature increase, might counteract and even overcompensate the additional rainfall and create a negative climatic water balance during summer. This highlights the importance of analyzing the seasonal variability of climate change not only the mean annual changes. Both, anthropogenic and natural factors control flow regime at the catchment scale. The impact of anthropogenic stressors on anastomosing system planform, has been extensively investigated in the study of Marcinkowski and Grygoruk (2017), and therefore, in this study we focus on the climate change impact.

Against this background, the objective of this paper is to assess the impact of projected climate change on average flow conditions in the anastomosing section of the River Narew, with the focus on low discharges in the main channel and the anabranches, which are threatened of extinction. Soil and Water Assessment Tool model (SWAT, Arnold et al., 1998) for the Narew catchment is used and coupled with the HEC-RAS one-dimensional unsteady flow model, built for the anastomosing section of the river (where channel extinction process is recognized to be in progress), including main channel and the anabranch. The study looks into projected changes for two future time horizons within the $21^{\text {st }}$ century (2021-2050 and 2071-2100) under the 
92 Representative Concentration Pathway (RCP) 4.5, using an ensemble of nine EURO-CORDEX 93 model scenarios (Jacob et al., 2014).

94

95

96

97

98

2. Materials and Methods

\subsection{Site description}

The Upper Narew is the sub-catchment of the largest Polish river basin - the Vistula (Fig. 1). It drains an area of $4231 \mathrm{~km}^{2}$ (of which $27 \%$ belong to Belarus) and is characterized by a flat relief with an average elevation of $152 \mathrm{~m}$ a.s.l. The prevailing type of soils in the catchment are sands and loamy sands, whereas heavy, impervious soils are rare. The land cover in the Upper Narew catchment is predominantly forested (43.6\%) and agricultural (41\%), whereas wetlands and grasslands occupy $16 \%$ of the area. The catchment is located in a temperate climatic zone with moderately warm summers (mean temperature in July $18^{\circ} \mathrm{C}$ ), cool winters (mean temperature in January $-2^{\circ} \mathrm{C}$ ), and an annual average precipitation total of ca. $600 \mathrm{~mm}$.

The Upper River Narew stretch, which was investigated in this study (Fig. 1C), is characterized by low-gradient $(0.0002 \mathrm{~m} / \mathrm{m})$ and anastomosing pattern. It is situated in the Narew National Park (NNP) for which Natura 2000 sites (under both Bird and Habitat directives) were established. Within the NNP (6810 ha), the river is characterized by a complex network of small interconnected channels (Gradziński et al., 2003). Vegetation cover within the NNP is dominated by early growth sedge and reed communities. In-stream vegetation densely overgrows channels during the summer season, but also survives to some extent the dormancy season, influencing the hydraulics of channels for the whole year. The flow regime (based on discharge data series from the Suraż gauging station spanning from 1951 to 2018) is characteristic for lowland snow/rainfall-fed rivers, with clearly dominating spring flooding, sourced by snowmelt occurring most commonly in April. Summer floods caused by heavy rain events are significantly lover. The average yearly discharge for the analyzed period is $15.4 \mathrm{~m}^{3} / \mathrm{s}$, whereas extreme events (i.e., minimum and maximum flows) equal $1.5 \mathrm{~m}^{3} / \mathrm{s}$ and $250 \mathrm{~m}^{3} / \mathrm{s}$, respectively. The number of days with flooding is diverse (from 0 to $119 ; 37$ on average) and depends majorly on the snow cover thickness in winter season.

This particular stretch has been selected for the analysis, as according to Marcinkowski et al. (2017a) the channel extinction process was recognized to be in progress there for the last few 
121 years. It is worth noting that in current conditions during the growing season on average nearly

$12298 \%$ of the flow is concentrated in the main channel (right-hand side reach on Fig. 1C) and only

$1232 \%$ is distributed to left-hand side anabranch. Such extremely low flows and unevenly distributed

124 discharge create favorable conditions for vegetation encroachment and channel sedimentation,

125 which in turn lead to the gradual closure of the side channels, what is observed in the field for the

126 last few years. Therefore, it has to be highlighted that if current hydrological conditions,

127 especially low flows during the vegetation period, remain stable in the coming decades, the

128 anastomosing system will most likely shift into single-channel planform. The extinction process

129 is in progress now and it might be assumed that it will be continued unless the low flows

130 increase.

1312.3 Integrated modelling framework

132 The IMF applied in this study consists of a catchment scale SWAT model and a river reach scale

133 HEC-RAS model. Hydrological SWAT model driven by climate change projections was used for

134 daily discharge calculations for the future time horizons: 2021-2050 (near future - NF), and

135 2071-2100 (far future - FF). For a baseline scenario, which determines a reference point for the

136 projected climate changes, historical (1971 -2000) bias-corrected climate model data was used.

137 In the study, flow condition changes were assessed at two different spatial scales: (1) at

138 catchment scale mean monthly flows were calculated (for all SWAT sub-basins) showing the

139 general impact of climate change on water resources in the area and (2) at reach scale daily

140 hydrographs (implemented in 1D HEC-RAS hydraulic model as an upstream boundary condition

141 and groundwater inflow from subcatchment) were calculated from the SWAT project. This way

142 SWAT-based simulations of daily flow could be directly transferred and routed in the HEC-RAS

143 stream network (Fig. 1C) as the flow hydrograph input, which allowed to assess the impact of

144 climate change on hydraulic conditions in the anastomosing section of the River Narew.

145 Projected flow hydrographs of models' ensemble as a SWAT model output can be found in the

146 raw supplementary material (Flow simulation files). As low flows prevail in summer and autumn

147 months, triggering anabranch loss (Marcinkowski et al., 2017a), HEC-RAS is only applied

148 during these periods. The resulting daily discharge was next reach-averaged and analyzed for

149 flow velocity. . Additionally, to assess not only the magnitude but also the duration of low flow

150 conditions, hydrographs derived from SWAT were statistically examined. Given that the channel 
151 loss process is triggered by low flow conditions a threshold value has been defined based on the

152 daily discharge observations from Suraż gauging stations (1952-2017), expressed as $\mathrm{Q}_{80}$ (with

$15380 \%$ exceedance probability). This particular exceedance probability has been selected for two

154 reasons: (1) according to Smakhtin (2001) flows within the range of 70-99\% time exceedance

155 are usually most widely used as design low flows, (2) collected discharge measurements used for 156 HEC-RAS model calibration correspond to $\mathrm{Q}_{80}$. Taking into account the $\mathrm{Q}_{80}$ flow (7 $\left.\mathrm{m}^{3} / \mathrm{s}\right)$, for

157 each climate model in the baseline, NF and FF horizons, the number of days lower than $\mathrm{Q}_{80}$ were 158 accumulated. Additionally, the mean value of flow of consecutive days below threshold was 159 calculated. The analysis scheme is presented in Fig. 2.

SWAT is a process-based, continuous-time model which simulates the movement of water, sediment, and nutrients on a catchment scale (Arnold et al., 1998). It is a comprehensive tool suitable for investigating the interaction between climate, land use and water quantity. It enables simulation of long-term impacts of climate changes on water, sediment, and nutrient loads in catchments with varied topography, land use, soils and management conditions. Spatially, the catchment area is divided into sub-basins and further into Hydrologic Response Units (HRU), which are the smallest spatially explicit units. Water balance as well as sediment and nutrient loads for each HRU are calculated at the land phase. Runoff is further aggregated to the subbasin level and routed through the stream network to the main outlet in order to obtain the total runoff for the river basin. SWAT has also a simplified groundwater flow component which partitions groundwater into two aquifer systems: a shallow, unconfined aquifer which contributes return flow to streams and a deep, confined aquifer which contributes return flow to streams outside the watershed. In this study, we build upon the existing SWAT model of the Upper Narew catchment (Marcinkowski et al., 2016).

Delineation of the catchment based on the 10-m resolution DEM resulted in division of the catchment into 243 sub-basins. Intersection of land cover map, soil map, and slope classes resulted in creation of 4509 HRUs. Daily precipitation and air temperature (minimum and maximum) data (1951-2013) were acquired from $5 \mathrm{~km}$ resolution gridded, interpolated using 
181 the Institute of Meteorology and Water Management (IMGW-PIB; Polish stations) (Berezowski

182 et al., 2016). The use of interpolated climate data in the SWAT model, as reported by Szcześniak 183 and Piniewski (2015) increased the model performance for a case study in Poland.

184 Calibration phase was conducted in SWAT-CUP using the SUFI-2 algorithm (Sequential 185 Uncertainty Fitting Procedure Version 2) where the Kling-Gupta efficiency (KGE) was used as 186 an objective function (Gupta et al., 2009). In the calibration and validation of the daily discharge, 187 ten flow gauges (data acquired from IMGW-PIB) were used. Calibration period was set to 1976188 1985, and the validation period was 1986-1991, which was dictated by the highest number of 189 observation records available in the catchment (Marcinkowski et al. 2016). Marcinkowski et al. 190 (2016) reported satisfactory values of goodness-of-fit measures across for all gauging stations 191 (median KGE above 0.7). Fig. 3 depicts the observed vs simulated daily discharge in the Suraż 192 gauging station (cf. Fig. 1), which is at immediate upstream to the HEC-RAS model created for 193 the anastomosing section of the River Narew.

195 In this study, SWAT was driven by climate forcing data from the CHASE-PL Climate 196 Projections: 5-km Gridded Daily Precipitation \& Temperature Dataset (Mezghani et al., 2016), 197 consisting of nine bias-corrected General Circulation Model - Regional Climate Model (GCM198 RCM) runs (involving four different GCMs and four different RCMs) provided within the 199 EURO-CORDEX experiment projected to the year 2100 under RCP4.5 (Piniewski et al., 2017). All bias-corrected values (quantile mapping method by Norwegian Meteorological Institute,

201

202 203 204 205 206 207 208 209 210 (Gudmundsson et al., 2012)) of precipitation and air temperature were available for three time slices: 1971-2000 (historical period), 2021-2050 (near future - NF), and 2071-2100 (far future FF). To deal with uncertainty caused by the use of different RCMs, a multi-model ensemble median approach was used.

\subsection{HEC-RAS}

HEC-RAS is a well-known hydrodynamic model for one and two-dimensional hydraulic calculations and is often used in calculating both steady and unsteady, gradually varied flow (Dysarz et al., 2019, Horrit and Bates, 2002). In addition, the HEC-RAS system solves movable boundary sediment transport computations and water quality analysis. In 1D hydrodynamic 
211 component model solves the full 1D St Venant equations for unsteady open channel flow with

212 the finite difference method, using a four point implicit box scheme (Brunner, 2016). Manning's

213 roughness coefficients are used to describe the flow resistance and were calibrated for the

214 analysed river branches.. HEC-RAS performs hydraulic calculations for a full network of natural

215 and constructed channels. Depending on the type of reach junction (flow split or flow rejoin) in a

216 river network, one equation of continuity of flow or equation continuity of stage is used as an

217 interior boundary equation.

218 2.5.1 Fieldwork and data collection

219 HEC-RAS (Brunner, 2016) model setup is strongly dependent on geometric and hydrological

220 data. Geometric data consisted of river cross-sectional geometry collected at periodic, uniformly

221 distributed (250 m intervals) stations along the selected, anabranching reach. The spacing of the

222 measured cross-sections is related to Narew river topography (Marcinkowski et al., 2017b). In

223 numerical model these cross-sections were used as a basic set for interpolating cross-section data

224 at finer spacing. The spacing of measured cross-sections in the investigated river reach fulfills

225 recommendation of Samuels (1990), that distance between two cross-sections in 1D hydraulic

226 model should be 10-20 times larger than bankfull surface width of a channel. In the analysed

227 river network the average width of the main channels and the anabranches during the low flow

228 condition is $17.61 \mathrm{~m}$. Samuels recommendations were based on a combination of common sense,

229 practical experience and mathematical equations. Additionally, results obtained by Castellarin et

230 al. (2009) using 1D model HEC-RAS were consistent with the guidelines suggested by Samuels

231 (1990).

232 Cross-sectional data was collected using Real-Time Kinematic GPS (GPS-RTK) (Cross-

233 sectional data available in raw supplementary material). Actual water surface profiles for

234 investigated study reach at low flow rates was surveyed in the summer season. It was

235 accomplished by surveying the water surface elevation at each cross-section using the GPS-

236 RTK. Discharge was measured using a hand-held electromagnetic water flow meter at two river

237 reaches (main channel and anabranch). The collected cross-sectional data, water surface level

238 and discharge were used for model setup, calibration and validation.

239

2.5.2 Model setup calibration and validation

Peer] reviewing PDF | (2019:12:43883:1:0:NEW 17 Apr 2020) 
240 Hydrodynamic modeling of the Narew River water flow was performed in HEC-RAS model. In

241 the hydrodynamic model, the river network was reproduced using four river reaches (cf. Fig.

242 1C). The Narew Upstream (NU) segment covers the upper section of the river from the cross

243 section located at $\mathrm{km} 05+470 \mathrm{~km}$ to the split of flow at a channel junction to Narew right (NR)

244 reach and Narew left (NL) reach, which represent the main Narew channel and its anabranch,

245 respectively. Both sections are then combined in the Narew downstream (ND) segment (cf. Fig.

246 1C). In the model, the NU reach has $400 \mathrm{~m}$ of length and was represented through 9 calculation

247 cross-sections. The NR segment with a length of $3.69 \mathrm{~km}$ is represented by 75 cross sections, and

248 the NL oxbow lake with a length of $4.715 \mathrm{~km}$ is described in the model with 95 cross-sections.

249 The ND segment ending the analyzed river network is $1.365 \mathrm{~m}$ long and consists of 28 cross-

250 sections. In the model, the average distance between calculation cross-sections is about $50 \mathrm{~m}$.

251 The upper boundary condition is formulated in the form of a flow hydrograph. The rating curve

252 describes downstream boundary condition. The inflow from subcatchment calculated by SWAT,

253 was applied in 1D hydraulic model as a hydrograph of uniform lateral inflow. It can be assumed

254 that in low flow condition, when river has a draining function, this inflow describes river -

255 groundwater interaction. The calibration and validation of the model was performed for

256 vegetation period, which differs significantly from dormancy season in the abundance of in-

257 stream vegetation. During the summer-autumn season vegetation overgrows side anabranches

258 causing high flow resistance and decreasing its capacity. The Manning's $n$ roughness coefficients

259 were calibrated for four river reaches in a way that a unique roughness value has been assigned

260 to the whole reach. In calibration process a trial and error method has been used. Trial and error

261 calibration involves repeated simulations while adjusting the model parameters until simulated

262 results match measured variables. Calibration included adjustment of Manning's coefficients for

263 four branches so that the model results agreed with field measurement of water level and mean

264 velocity. The initial Manning's coefficient were consistent with values estimated by

265 Marcinkowski et al. (2017). Following the initial set $\left(\mathrm{n}_{\mathrm{NU}}=0.03 ; \mathrm{n}_{\mathrm{NR}}=0.027 ; \mathrm{n}_{\mathrm{NL}}=0.089 ; \mathrm{n}_{\mathrm{ND}}\right.$

$266=0.03$ ) the Manning's coefficients were manually adjusted to minimize the difference between

267 the simulated and observed water level and the measured and simulated mean water velocity at

268 nine measurement points in ND, NR and NL sections (cf. Fig.1).

269 3. Results 
270

271 Projected mean annual temperature in the Upper Narew catchment is expected to increase by

272 approximately $1.2^{\circ} \mathrm{C}$ (ensemble range $0.8^{\circ} \mathrm{C}-1.6^{\circ} \mathrm{C}$ ) in $\mathrm{NF}$ and $2.1^{\circ} \mathrm{C}$ (ensemble range $1.5^{\circ} \mathrm{C}-$

274 variation, the highest change is expected to occur in November-March $\left(2.4^{\circ} \mathrm{C}\right.$, ensemble range

$\left.2752.1^{\circ} \mathrm{C}-2.6^{\circ} \mathrm{C}\right)$ and lowest in April-October $\left(1.7^{\circ} \mathrm{C}\right.$, ensemble range $\left.1.5^{\circ} \mathrm{C}-1.9^{\circ} \mathrm{C}\right)$

276 (Marcinkowski et al., 2017b).

277 Annual total precipitation is projected to increase by $5.6 \%$ in the NF and by $9.5 \%$ in the FF, on

278 the annual basis. The seasonal patterns show a relatively high increase in winter and spring and

279 mixed response (both increase and decrease cases) in summer and autumn. In the FF the spring

280 precipitation increase is distinctly higher than in other seasons, exceeding 20\% (Marcinkowski et

281 al., 2017b) (Fig. 4).

282 SWAT model simulations indicate that the median of projected changes in average water

283 discharge, at the annual basis and catchment scale, is expected to increase by $11 \%$ and $25 \%$ in

284 the NF and FF, respectively. Monthly patterns showed the most pronounced increase occurring

285 in December-March, with the ensemble median reaching 17\% and 35\% for NF and FF,

286 respectively. In April-November period significantly lower increase in discharge is observed,

287 reaching $7 \%$ and $23 \%$ for the NF and FF, respectively (Fig. 5). Additionally, more extreme and

288 outlying values (both low and high) are noted for the future time horizons, compared to historical

289 period. High flows might be attributed to occurrence of extremely heavy rain events in projected

290 rainfall patterns and low flows to increase of air temperature triggering the increase of

291 evapotranspiration.

292

3.2 HEC-RAS model performance

293

A simulated split flow at channel junction was compared with observations in the NR and NL

294

reaches. In the calibration process for a discharge of $7.4 \mathrm{~m}^{3} / \mathrm{s}$, the error of the flow distribution is

295

$0.7 \%$ and $11 \%$ for section NR and NL respectively. The average error of the water table in the

296 river reaches varies from $0.03 \mathrm{~m}$ to $0.05 \mathrm{~m}$. The mean error of simulated water velocity is $6 \%$,

$2977 \%, 14 \%$ for the ND, NR and NL segments respectively (Table 1). The model accuracy

298 discussed above was obtained for the following set of Manning's coefficients: $\mathrm{n}_{\mathrm{NU}}=0.028 ; \mathrm{n}_{\mathrm{NR}}$

$299=0.028 ; \mathrm{n}_{\mathrm{NL}}=0.1 ; \mathrm{n}_{\mathrm{ND}}=0.035 \mathrm{~m}^{-1 / 3} / \mathrm{s}$. These values are in the range of the roughness 
300

301

302

303

304

305

306

307

308

309

310

311

312

313

314

315

316

317

318

319

320

321

322

323

324

325

326

327

328

329

coefficients used in other models for the analyzed section of the Narew River (Marcinkowski et al., 2018b). Verification of the developed model was based on measurements of the water level and water velocity performed at a discharge $10.5 \mathrm{~m}^{3} / \mathrm{s}$. In this case, the errors for the flow distribution are $0.9 \%$ and $9 \%$ for the sections NR and NL respectively. The average error of the water table varies from $0.04 \mathrm{~m}$ to $0.07 \mathrm{~m}$. The mean error of simulated water velocity is $7 \%, 3 \%$, $9 \%$ for the ND, NR and NL river reaches respectively (Table 2). The obtained errors are considered acceptable to allow the use of the model to simulate the unsteady flow during the vegetation period. Then the developed hydrodynamic model was used to simulate the flow for the long historical period 1973-2000 and climate change scenarios for years 2070-2100. In these simulations, the upper boundary condition in the form of a flow hydrograph was calculated in the SWAT hydrological model.

3.3 Reach scale changes in flow condition

At the reach scale the flow condition changes were calculated based on the SWAT model simulations for the particular sub-basin, that spatially overlaps with the HEC-RAS hydraulic model. As indicated in Fig. 6 the duration of low flows changes significantly when comparing historical period and future horizons. Considering the annual values (Fig.6B), a gradual decrease from 151 (baseline) to 135 (NF) and 123 days (FF) is observed. However, the change is not uniform across the year and varies notably between each month (Fig.6A). In general, for November-July a clear drop in the duration of low flows in observed reaching $30 \%$ and $50 \%$ (ensemble median) for NF and FF, respectively. However, for August - October for the NF slight increase in duration of low flows is noted (8\%). Such trend subsides in FF where again the decrease is observed, but significantly lower than for winter, reaching only $20 \%$. The analysis of mean flow values of consecutive days below threshold indicate a gradual increase at the annual level from historical period to future horizons (Fig.6D). However, the change is not uniform across the year. In general, higher increase is observed for FF compared to NF and the highest increase occurs for February-May in both time horizons. What is noteworthy, the mean value of flow for days below $\mathrm{Q}_{80}$ seems to stay at almost the same level in NF for August - October (Fig.6C).

Further analysis included assessment of low flow magnitude changes, which for summer and autumn seasons was modelled in HEC-RAS using daily flow hydrographs derived from SWAT. 
330 Reach-averaged discharge and flow velocity is presented separately for the main channel and the

331 anabranch. Simulations derived from SWAT indicate that both discharge rate and mean flow

332 velocity slightly increase in NF (3\% for ensemble median) andFF ( $5 \%$ for ensemble

333 median)(Fig.7). Based on T-student test NF changes of discharge and flow velocity were not

334 statistically significant ( $\mathrm{p}$ value of 0.16 and 0.15 , respectively) and the FF changes were

335 statistically significant ( $\mathrm{p}$ value of 0.0001 and 0.001 , respectively).

336 4. Discussion

337

338

4.1 Anastomosing river perspectives under climate change

339

Conservation of anastomosing rivers worldwide, although extremely important nowadays, has not been addressed in many studies. The success of their conservation depends on finding and steering the appropriate key factors, which differ from stream to stream and site to site (Verdonschot and Nijboer, 2002). Marcinkowski et al. (2017a) pointed out the low flow to be the main stressor triggering the loss of anastomosing channels in the NNP. In this study flow conditions were analyzed in terms of duration and magnitude, using a cascade of modelling driven by climate change projections. It was due to that Regional Climate Model (RCM) data operates at coarse scale, whereas in river conservation programs particular river reaches of fine scale are targeted. Results were presented at catchment (using SWAT) and reach (using HECRAS) scale on annual and monthly basis. Catchment-averaged mean annual duration of low flows $\left(\mathrm{Q}\right.$ below $\left.\mathrm{Q}_{80}\right)$ was projected to decrease and mean flow to increase in both future time horizons. Conclusions drawn on the annual basis results suggest that hydrological conditions might improve in future. However, more detailed monthly analysis indicated that for AugustOctober, when according to Marcinkowski et al. (2017a) the loss of anastomoses is the most intense, duration of flows below $\mathrm{Q}_{80}$ increases and mean flow in NF is projected to remain at the same level as currently. Projected increase in precipitation and flow is distributed mainly to winter and spring season, when the vegetation is scarce and the potential of overgrowing the anastomoses very low. In a consequence, near future hydrological conditions are not projected to improve in the most sensitive (in terms of anastomoses loss) period of the year. 
358 Reach-scale HEC-RAS simulations of water flow conditions in the anastomosing sections of the 359 river Narew indicate very low flow velocity $(0.09 \mathrm{~m} / \mathrm{s}$ - ensemble median) in the anabranch, 360 which remains the same in NF and only slightly increases in FF $(0.1 \mathrm{~m} / \mathrm{s}-$ ensemble median).

361 Such hydraulic conditions lead to in-stream vegetation development. Typically the abundance of 362 macrophytes are stimulated at low velocities and their growth is restricted at higher velocities 363 (Marcinkowski et al., 2017a, 2018b). It is due to the fact that water velocity affects 364 photosynthesis through the regulation of the availability of dissolved substances (Madsen et al., 365 2001). It has been reported that the photosynthetic and nutrient uptake rates of in-stream 366 macrophytes are positively correlated with low water velocities $(0-0.1 \mathrm{~m} / \mathrm{s})$ (Marshall and 367 Westlake, 1990; Madsen et al., 2001). The prospect of a further reduction of river flow velocity 368 in NF horizon suggest further degradation on anastomosing system in coming decades.

369 One of the major issues in freshwater ecosystems conservation is that the adaptive management 370 must be applied on time to be useful. Therefore, delayed detectability of a climate change signal

371 might cause the implemented practices to be ineffective or bring the economic and ecologic 372 losses. It is well known that the climate models themselves, although continuously improved, are 373 to some extent uncertain (Ito et al., 2020). However, reasonable conservation management may 374 consider the use of model projections to guide future interventions. In anastomosing Narew case 375 the simulations at reach scale that were run under consideration of climate projections and 376 process-based catchment modelling, indicate that most possibly by the end of 2050 (NF) 377 hydrological conditions, and consequently the sediment transport potential, will not improve, 378 which means that by that time the most anastomosing channels in the NNP will be aggraded and 379 fully colonized by vegetation. Marcinkowski et al. (2019) conducted a model-based assessment 380 of the hydraulic efficiency of channel vegetation removal, dredging and water damming, in 381 increasing stream capacity and sediment transport potential in the anastomosing section of the NNP. Results of this paper indicated that summer flow conditions in NF will be comparable to current, which means that flow boundary conditions used in the model of Marcinkowski et al. (2019) are applicable to NF flow conditions. Consequently, their simulations of stream capacity and sediment transport potential might be used in this study to accurately reflect future hydraulic conditions and potential efficiency of conservation measures. Projected hydraulic conditions suggest that least invasive in-stream vegetation removal in the future will not increase the 388 sediment transport potential preventing from river bed aggradation, and consequently, stream 
389

390

391

392

393

394

395

396

397

398

399

400

401

402

403

404

405

406

407

408

409

410

411

412

413

414

415

416

417

418

colonization by plants. Sufficient increase in stream flow capacity might be achieved only by implementing high invasive channel dredging and water damming, provided that they are implemented relatively soon. Such alterations of hydraulic properties in anastomoses might result in a significant increase in sediment transport potential, which ensures the stability of restoration eliminating the main cause of channels extinction i.e. excessive sediment deposition and plants colonization.

\subsection{Study limitations}

In this study we used coupled hydrological and hydraulic models to test the impact of climate change on flow conditions in the anastomosing section of the NNP. Designed methodological approach as well and tools and the datasets used are burdened with some limitations. First of all, it has to be mentioned that low flows, which are of special concern in this study, are mainly triggered by groundwater, whereas both SWAT and HEC-RAS models are not addressing this flow component in sufficient detail. To reduce the errors while transferring the projected discharge values from SWAT to HEC-RAS beside the daily stream hydrograph, additionally, a groundwater flow (generated by groundwater recharge) from the direct sub-catchment area of the anastomosing section, was added to the HEC-RAS domain. According to Bates et al. (2008) hydrological changes to European rivers caused by climate change are strongly related stream flow type. Following their findings, for catchments dominated by groundwater flow (Narew case), a decline in groundwater recharge is expected which poses a greater risk of groundwater and surface water drought in these catchments. Therefore, Simplistic approach for groundwater simulation presented in SWAT and HEC-RAS which might give unreliable results in terms of the magnitude of groundwater flow contribution to the channel, is rather consistent with the overall direction presented by Bates et al. (2008).

\section{Conclusion}

Coupled hydrological and hydraulic modelling conducted in this study indicated that low flow conditions in the anastomosing section of the Narew National Park will remain relatively stable in the near future and will slightly improve in far future. Duration of low flows, although projected to decrease on an annual basis, will increase for August-October, when the loss on anastomoses was found to be the most intense. Extremely low flow velocities in the anastomosing arm $(<0.1 \mathrm{~m} / \mathrm{s})$ nowadays and under future projections seem to remain stable. Such 
419 conditions are preferable for in-stream vegetation development, as typically the abundance of

420 macrophytes are stimulated at low velocities and their growth is restricted at higher velocities.

421 The perspective of further degradation on anastomosing system in coming decades requires

422 actions to be undertaken by freshwater ecosystem managers. Our study, although burdened with

423 limitations and uncertainties might serve as a reference for expected future flow conditions.

424 6. References

425 Arnold, J. G., Srinivasan, R., Muttiah, R. S., Williams, J. R. Large-area hydrologic modeling and 426 assessment: part I. model development. Journal of the American Water Resources Association $4271998,34(1), 73-89$.

428 Bates, B. C., Kundzewicz, Z. W., Wu, S., Palutikof, J. P. \& (Eds). 2008. Climate change and 429 water. Technical paper of the intergovernmental panel on climate change, IPCC secretariat, 430 Geneva.

431 Berezowski, T.; Szcześniak, M.; Kardel, I.; Michałowski, R.; Okruszko, T.; Mezghani, A.;

432 Piniewski, M. CPLFD-GDPT5: High-resolution gridded daily precipitation and temperature data 433 set for two largest Polish river basins. Earth Syst. Sci. Data 2016, 8, 127-139.

434 Bertoldi,W.; Siviglia, A.; Tettamanti, S.; Toffolon, M.; Vetsch, D.; Francalanci, S. Modeling 435 vegetation controls on fluvial morphological trajectories. Geophys. Res. Lett. 2014, 41, 71674367175.

437 Björn Guse a, Jochem Kail, Johannes Radinger, Maria Schröder, Jens Kiesel, Daniel Hering, 438 ChristianWolter, Nicola Fohrer. 2015 Eco-hydrologic model cascades: Simulating land use and 439 climate change impacts on hydrology, hydraulics and habitats for fish and macroinvertebrates 440 Science of the Total Environment 533 (2015) 542-556

441 Brunner, G.W. HEC-RAS River Analysis System Hydraulic Reference Manual; US Army Corps 442 of Engineers; Report No. CPD-69; Hydrologic Engineering Center (HEC): Davis, CA, USA, 4432016.

444 Castellarin, A.,et al., 2009. Optimal cross-sectional spacing in Preissmann scheme 1D

445 hydrodynamic models. Journal of Hydraulic Engineering, 135 (2), 96-105.

446 doi:10.1061/(ASCE)0733-9429(2009)135:2(96). 
447 Dysarz T, Wicher-Dysarz J, Sojka M, Jaskuła J (2019) Analysis of extreme flow uncertainty

448 impact on size of flood hazard zones for the Wronki gauge station in the Warta river. Acta

449 Geophysica 67:661-676

450 Giri, S., Arbab, N.N., Lathrop, R.G., 2019. Assessing potential impacts of climate and land use 451 change on water fluxes and sediment transport in a loosely coupled system. Journal of 452 Hydrology 577, 123955.

453 Gudmundsson, L.; Bremnes, J.B.; Haugen, J.E.; Engen-Skaugen, T. Technical Note:

454 Downscaling RCM precipitation to the station scale using statistical transformations-A

455 comparison of methods. Hydrol. Earth Syst. Sci. 2012, 16, 3383-3390.

456 Gupta, H.V.; Kling, H.; Yilmaz, K.K.; Martinez, G.F. Decomposition of the mean squared error 457 and NSE performance criteria: Implications for improving hydrological modelling. J. Hydrol. $4582009,377,80-91$.

459 Horritt, MS ; Bates ,PD., Evaluation of 1D and 2D numerical models for predicting river flood 460 inundation. In: Journal of Hydrology. 2002 ; Vol. 268, No. 1-4. pp. 87-99.

461 Ito, R., Shiogama, H., Nakaegawa, T., Takayabu, I. 2020. Uncertainties in climate change 462 projections covered by the ISIMIP and CORDEX model subsets from CMIP5. Geosci. Model 463 Dev., 13, 859-872.

464 Jacob, D.; Petersen, J.; Eggert, B.; Alias, A.; Christensen, O.B.; Bouwer, L.M.; Braun, A.; 465 Colette, A.; Déqué, M.; Georgievski, G.; et al. EURO-CORDEX: New high-resolution climate 466 change projections for European impact research. Reg. Environ. Chang. 2014, 14, 563-578

467 Jähnig, S.C., Kuemmerlen, M., Kiesel, J., Domisch, S., Cai, Q., Schmalz, B. and Fohrer, N. 468 2012. Modelling of riverine ecosystems by integrating models: conceptual approach, a case study 469 and research agenda. Journal of Biogeography 39(12), 2253-2263Kail J, Guse B, Radinger J, 470 Schröder M, Kiesel J, Kleinhans M, et al. (2015) A Modelling Framework to Assess the Effect of 471 Pressures on River Abiotic Habitat Conditions and Biota. PLoS ONE 10(6): e0130228. 472 doi:10.1371/journal.pone.0130228 
473 Kharel G, Kirilenko A. 2018. Comparing CMIP-3 and CMIP-5 climate projections on flooding

474 estimation of Devils Lake of North Dakota, USA. PeerJ 6:e4711

475 https://doi.org/10.7717/peerj.4711

476 Kiesel, J., Schmalz, B., Brown, G.L., Fohrer, N., 2013. Application of a hydrological-hydraulic

477 modelling cascade in lowlands for investigating water and sediment fluxes in catchment, channel

478 and reach. J. Hydrol. Hydromech. 61, 334-346.

479 Kingsford, T.K. 2011. Conservation management of rivers and wetlands under climate change -

480 a synthesis. Marine and Freshwater Research 62, 217-222

481 Kleinhans, M.G., de Haas, T., Lavooi, E., Makaske, B., 2012. Evaluating competing hypotheses

482 for the origin and dynamics of river anastomosis. Earth Surf. Process. Landf. 37: 1337-1351.

483 Krysanova, V., Kundzewicz, Z.W., Piniewski, M., 2016 Assessment of climate change impacts 484 on water resources W: V.P. Singh (Ed.) Handbook of applied hydrology, Nowy Jork : McGraw485 Hill Education, s. 148.1-148.12

486 Kundzewicz, Z.W., Piniewski, M., Mezghani, A., Okruszko, T., Pińskwar, I., Kardel, I., Hov, Ø., 487 Szcześniak, M., Szwed, M., Benestad, R.E., Marcinkowski, P., Graczyk, D., Dobler, A., Førland, 488 E.J., O’Keefe, J., Choryński, A., Parding, K.M. and Haugen, J.E. 2018 Assessment of climate 489 change and associated impact on selected sectors in Poland. Acta Geophysica , 66(6), 15094901523 ,

491 Lewin, J., 2010. Medieval environmental impacts and feedbacks: the lowland floodplains of 492 England and Wales. Geoarchaeology 25:267-311

493 Madsen JD, Chambers PA, James WF, Koch EW, Westlake DF. Theinteraction between water 494 movement, sediment dynamics andsubmersed macrophytes. Hydrobiologia 2001;444:71-84.

495 Makaske, B., Lavooi, E., de Haas, T., Kleinhans,M.G., Smith, D.G., 2017. Upstream control of 496 river anastomosis by sediment overloading, upper Columbia River, British Columbia, Canada. 497 Sedimentology http://dx.doi.org/10.1111/sed.12361.

498 Marcinkowski, P.; Giełczewski, M.; Okruszko, T. 2018a. Where might the hands-off protection 499 strategy of anastomosing river lead? A case study of the Narew National Park. Park. Pol. J. 500 Environ. Stud. 27, 2647-2658. 
501 Marcinkowski, P.; Grabowski, R.C.; Okruszko, T. 2017a. Controls on anastomosis in lowland

502 river systems: towards process-based solutions to habitat conservation. Science of the Total 503 Environment, 609, 1544-1555.

504 Marcinkowski, P.; Kiczko, A.; Okruszko, T. 2017b Modeling of water flow in multi-channel 505 river system in the Narew National Park. Ann. Warsaw Univ. Life Sci. SGGW Land Reclam., $50649,167-177$.

507 Marcinkowski, P.; Grygoruk, M. 2017. Long-Term Downstream Effects of a Dam on a Lowland 508 River Flow Regime: Case Study of the Upper Narew. Water (2017), 9, 783.

509 Marcinkowski P, Kiczko A, Okruszko T. 2018b. Model-Based Analysis of Macrophytes Role in 510 the Flow Distribution in the Anastomosing River System. Water, 10, 953.

511 Marcinkowski P, Kiczko A, Okruszko T. 2019. Model-based evaluation of restoration measures 512 efficiency in the anastomosing section of the River Narew. Ecological Engineering 130, $213-$ 513227.

514 Marcinkowski, P.; Piniewski, M.; Kardel, I.; Srinivasan, R.; Okruszko, T. 2016. Challenges in 515 modelling of water quantity and quality in two contrasting meso-scale catchments in Poland. J. 516 Water Land Dev., 31, 97-111.

517 Marcinkowski, P.; Piniewski, M.; Kardel, I.; Szcześniak, M.; Benestad, R.; Srinivasan, R.; Ignar, 518 S.; Okruszko, T. 2017b. Effect of Climate Change on Hydrology, Sediment and Nutrient Losses 519 in Two Lowland Catchments in Poland. Water 9, 156.

520 Marshall EJP, Westlake DF. Water velocities around plants in chalkstreams. Folia Geobot 521 Phytotaxon 1990;25

522 Maslin, M.; Austin, P. Uncertainty: Climate models at their limit? Nature 2012, 486, 183-184. 523 Mezghani, A.; Dobler, A.; Haugen, J.H. CHASE-PL Climate Projections: 5-km Gridded Daily 524 Precipitation \& Temperature Dataset (CPLCP-GDPT5). 2016. Available online:

525 http://data.4tu.nl/repository/uuid:e940ec1a-71a0-

526 449e-bbe3-29217f2ba31d 
527 Millennium Ecosystem Assessment (2005). 'Ecosystems and Human Wellbeing: A Framework

528 for Assessment.' (Island Press: Washington, DC.)

529 Mioduszewski W., Napiórkowski J., Okruszko T. 2014. Narew National Park Protection Plan

530 Białystok Narwiański Park Narodowy [In Polish].

531 Napoli, M., Massetti, L., Orlandini, S. 2017. Hydrological response to land use and climate

532 changes in a rural hilly basin in Italy. CATENA, 157,1-11

533 Nicholas, A. Morphodynamic diversity of the world's largest rivers. Geology 2013, 41, 475-478.

534 Ormerod, S.J., 2009. Climate change, river conservation and the adaptation challenge. Aquatic

535 Conserv: Mar. Freshw. Ecosyst. 19: 609-613.

536 Ostfeld, A., Barchiesi, S., Bonte, M., Collier, C.R., Cross, K., Darch, G., Farrell, T.A., Smith, 537 M., Vicory, A., Weyand, M., Wright, J., 2012. Climate change impacts on river basin and

538 freshwater ecosystems: some observations on challenges and emerging solutions. J. Water Clim.

539 Change $3(3), 171-184$

540 Piniewski, M., Mezghani, A., Szcześniak, M., Kundzewicz, Z.W. 2017 Regional projections of

541 temperature and precipitation changes: Robustness and uncertainty aspects. Meteorologische

542 Zeitschrift, 26(2), 223-234, doi: 10.1127/metz/2017/0813

543 Samuels, P.G., 1990. Cross-section location in 1-D models.In: WhiteW.R. ed.Proceedings of

544 international conference on riverflood hydraulics. Chichester: John Wiley, 339-350.

545 Schuurman, F.; Marra, W.A.; Kleinhans, M.G. Physics-based modeling of large braided sand-

546 bed rivers: Bar pattern formation, dynamics, and sensitivity. J. Geophys. Res. Earth Surf. 2013,

$547 \quad 118,2509-2527$

548 Smakhtin, V.U. 2001. Low flow hydrology: a review. Journal of Hydrology 240, 3-4, 147-186.

549 Szcześniak, M.; Piniewski, M. 2015. Improvement of Hydrological Simulations by Applying

550 Daily Precipitation Interpolation Schemes in Meso-Scale Catchments. Water, 7, 747-779

551 Tamm, O., Maasikamäe, S., Padari, A., Tamm, T. 2018. Modelling the effects of land use and

552 climate change on the water resources in the eastern Baltic Sea region using the SWAT model.

553 CATENA $167,78-89$ 
554 Verdonschot, P., Nijboer, R. 2002. Towards a decision support system for stream restoration in 555 the Netherlands: an overview of restoration projects and future needs. Hydrobiologia 478, 131$556 \quad 148$

557 Visser Annie Gallagher, Lindsay Beevers, Sandhya Patidar. 2019. A coupled modelling

558 framework to assess the hydroecological impact of climate change. Environmental Modelling 559 and Software 114 (2019) 12-28

560 Walter, R.C., Merritts, D.J., 2008. Natural streams and the legacy of water-powered mills. 561 Science 319:299-304. 
Figure 1

Case study (A- location, B-land use, C-river network, D- vegetation type

NU - Narew upstream reach, ND - Narew downstream reach, NL - Narew left reach, NR Narew right reach 


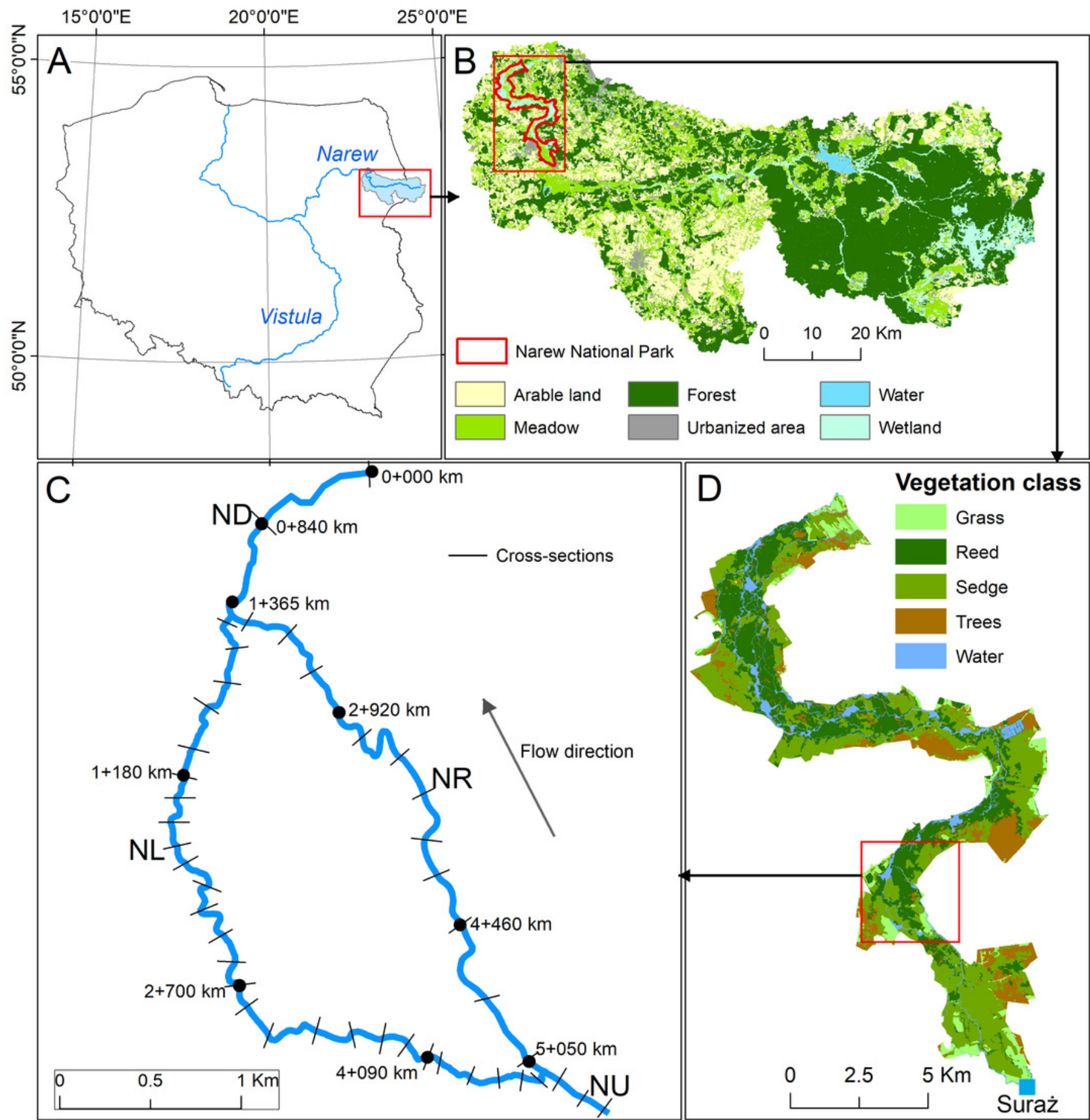


Figure 2

Workflow scheme

Field measurements:

- River cross-sections

- Water levels

- Hydrometric measuremets
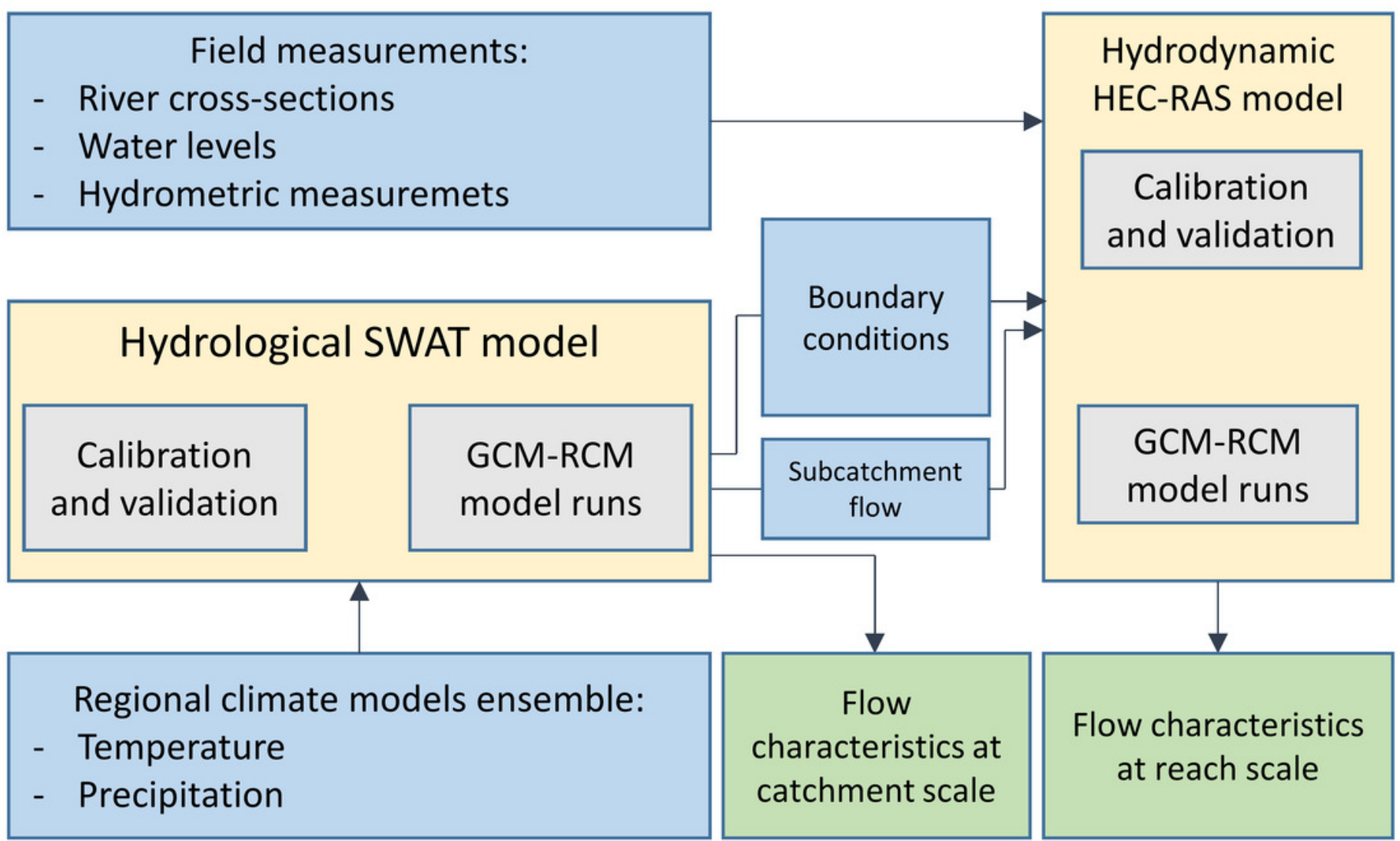
Figure 3

Observed vs simulated discharge in the Suraż gauging station in the calibration and validation period.

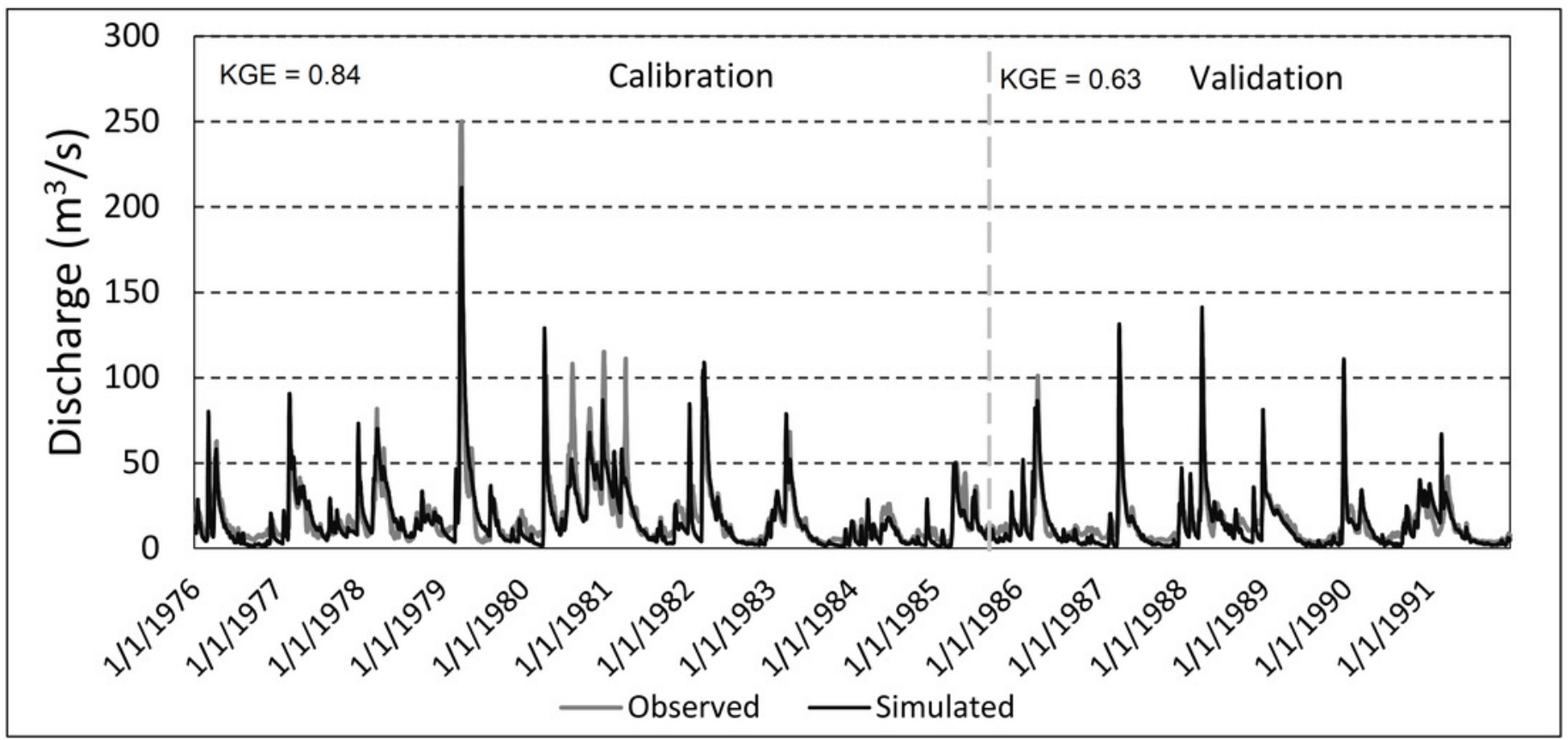


Figure 4

Projected mean monthly (A) and annual (B) sum of precipitation and mean monthly (C) and annual (D) air temperature in the Upper Narew catchment.

Light grey color denotes baseline, medium grey - NF and dark grey - FF horizon; squares denote median values, boxes $-1^{\text {st }}$ to $3^{\text {rd }}$ quartile values, whiskers - non outlier range, circles outliers, asterisk - extremes 

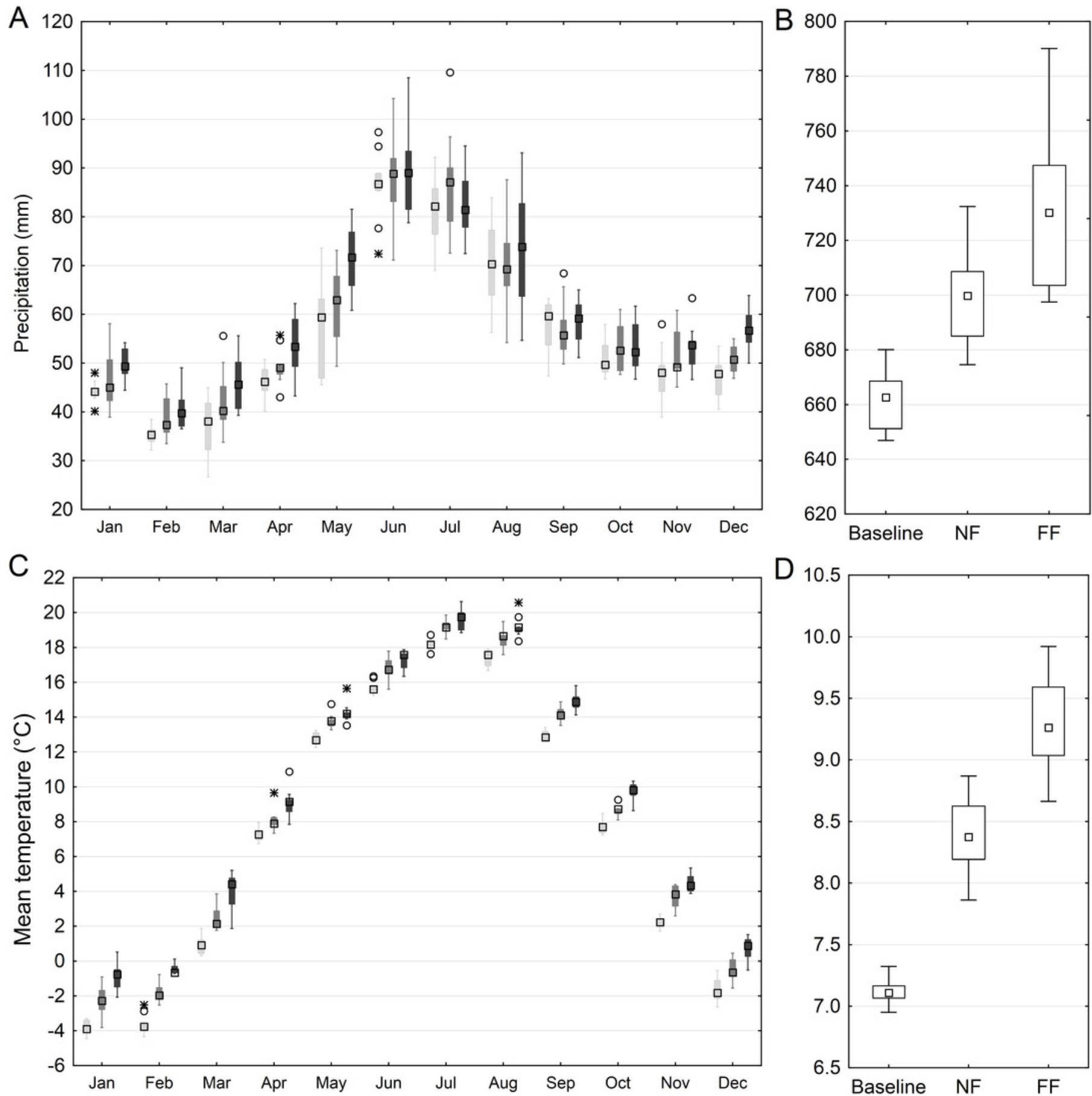
Figure 5

Simulated mean monthly (A) and annual (B) discharge at the main outlet of the Upper Narew catchment.

Light grey color denotes baseline, medium grey - NF and dark grey - FF horizon; squares denote median values, boxes $-1^{\text {st }}$ to $3^{\text {rd }}$ quartile values, whiskers - non outlier range, circles outliers, asterisk - extremes
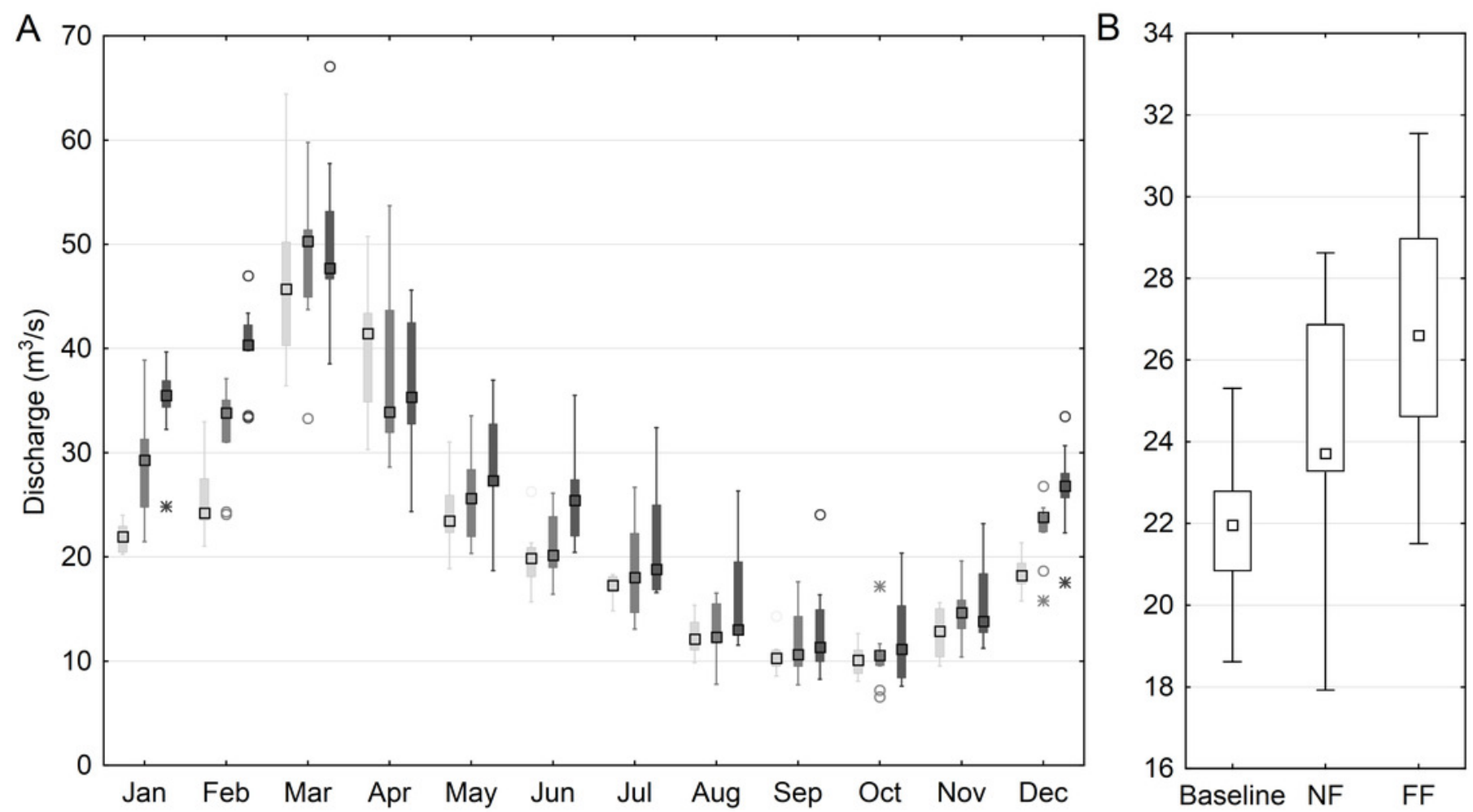


\section{Figure 6}

Mean monthly (A) and annual (B) number of days with low discharge $\left(Q<Q_{80}\right)$ for the anastomosing reach of the River Narew based on SWAT simulation and the mean monthly (C) and annual (D) value of flow of consecutive days below $\mathrm{Q}_{80}$.

NOD stands for number of days, light grey color denotes baseline, medium grey - NF and dark grey - FF horizon; squares denote median values, boxes $-1^{\text {st }}$ to $3^{\text {rd }}$ quartile values, whiskers - non outlier range, circles - outliers, asterisks - extremes 

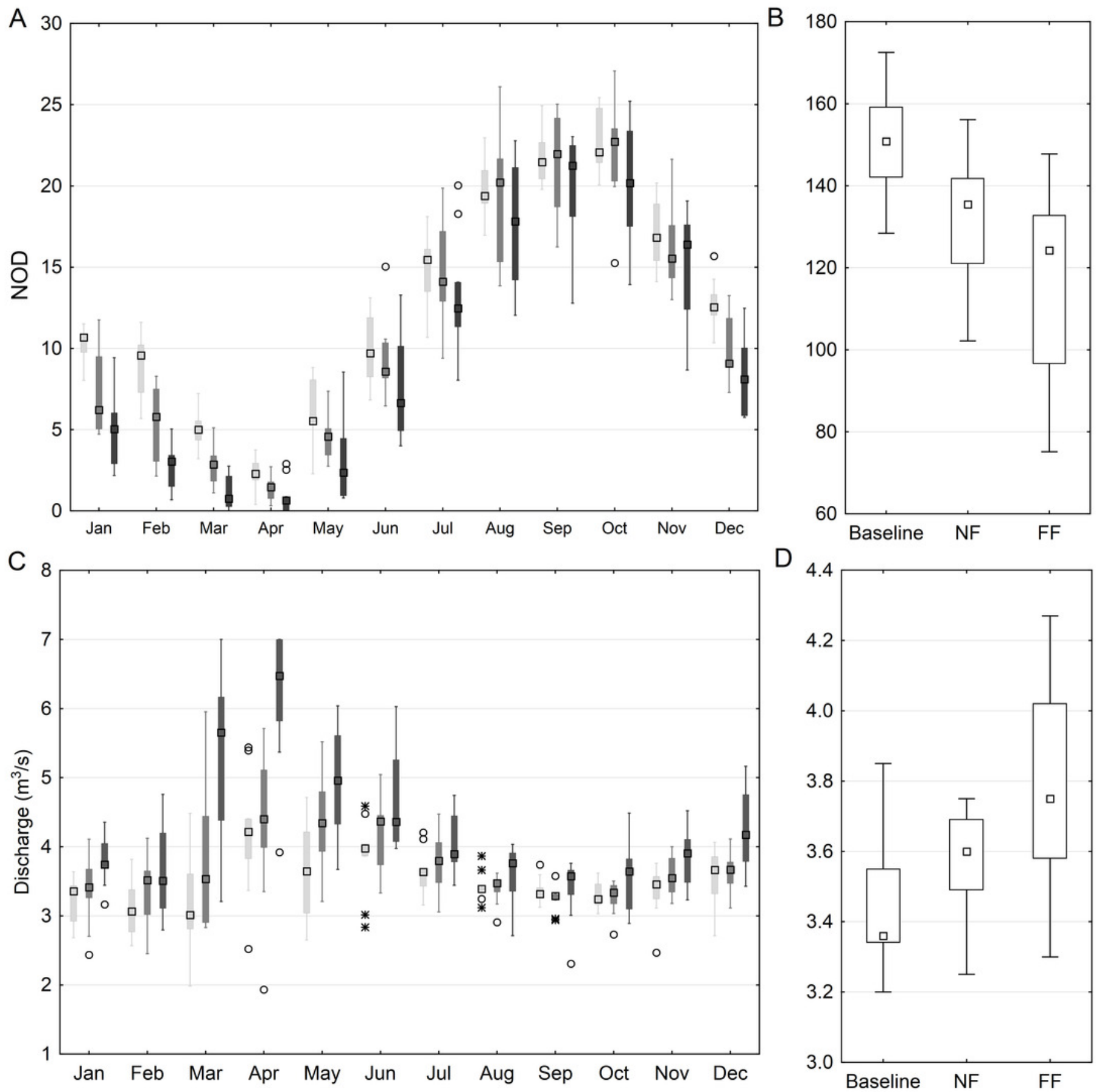


\section{Figure 7}

HEC-RAS model simulations of hydraulic condition changes in the anabranch $(A, C)$ and the main channel $(B, D)$.

Squares denote median values, plus marks - mean values, boxes $-1^{\text {st }}$ to $3^{\text {rd }}$ quartile values, whiskers - non outlier range, circles - outliers, asterisks - extremes 

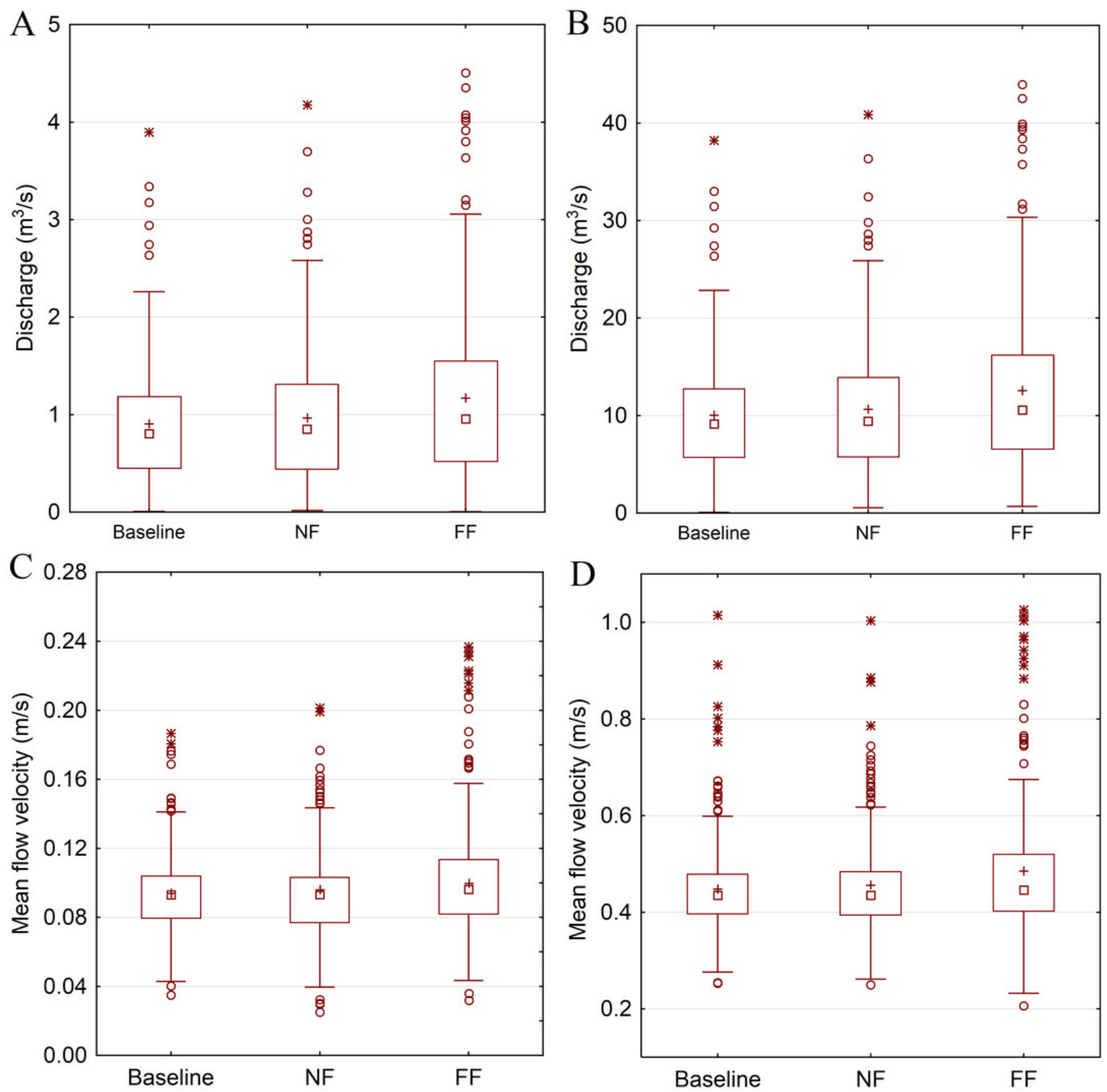


\section{Table 1 (on next page)}

Model errors (calibration run $\mathrm{Q}=7.4 \mathrm{~m}^{3} / \mathrm{s}$ )

Q -discharge, E - mean error in river reach, index $\mathrm{m}$ - model result, $\mathrm{v}$ - velocity, $\mathrm{H}$ - water level 


\begin{tabular}{|c|c|c|c|c|c|c|c|c|c|c|}
\hline Reach & $\mathrm{km}$ & $\begin{array}{c}\mathrm{Q} \\
{\left[\mathrm{m}^{3} / \mathrm{s}\right]}\end{array}$ & $\begin{array}{c}\mathrm{Q}_{\mathrm{m}} \\
{\left[\mathrm{m}^{3} / \mathrm{s}\right]}\end{array}$ & $\begin{array}{c}\mathrm{E}_{\mathrm{Q}} \\
{\left[\mathrm{m}^{3} / \mathrm{s}\right]}\end{array}$ & $\begin{array}{c}\mathrm{H} \\
{[\mathrm{m}} \\
\text { a.s.l } 1]\end{array}$ & $\begin{array}{c}\mathrm{H}_{\mathrm{m}} \\
{[\mathrm{m} \text { a.s.l] }}\end{array}$ & $\begin{array}{c}E_{H} \\
{[\mathrm{~m}]}\end{array}$ & $\begin{array}{c}\mathrm{V} \\
{[\mathrm{m} / \mathrm{s}]}\end{array}$ & $\begin{array}{c}\mathrm{V}_{\mathrm{m}} \\
{[\mathrm{m} / \mathrm{s}]}\end{array}$ & $\begin{array}{c}E_{v} \\
{[\mathrm{~m} / \mathrm{s}]}\end{array}$ \\
\hline \multirow{3}{*}{ ND } & $0+000$ & \multirow{3}{*}{7.4} & \multirow{3}{*}{7.40} & \multirow{3}{*}{0.0} & 115.18 & 115.16 & \multirow{3}{*}{0.05} & 0.43 & 0.46 & \multirow{3}{*}{0.02} \\
\hline & $0+840$ & & & & 115.38 & 115.42 & & 0.41 & 0.43 & \\
\hline & $1+365$ & & & & 115.48 & 115.57 & & 0.40 & 0.42 & \\
\hline \multirow{3}{*}{ NR } & $2+920$ & \multirow{3}{*}{6.95} & \multirow{3}{*}{6.85} & \multirow{3}{*}{0.1} & 115.79 & 115.83 & \multirow{3}{*}{0.03} & 0.36 & 0.38 & \multirow{3}{*}{0.03} \\
\hline & $4+460$ & & & & 116.09 & 116.07 & & 0.37 & 0.41 & \\
\hline & $5+050$ & & & & 116.20 & 116.16 & & 0.35 & 0.33 & \\
\hline \multirow{3}{*}{ NL } & $1+180$ & \multirow{3}{*}{0.45} & \multirow{3}{*}{0.55} & \multirow{3}{*}{0.1} & 115.66 & 115.71 & \multirow{3}{*}{0.04} & 0.04 & 0.05 & \multirow{3}{*}{0.01} \\
\hline & $2+700$ & & & & 115.89 & 115.93 & & 0.07 & 0.08 & \\
\hline & $4+090$ & & & & 116.10 & 116.06 & & 0.05 & 0.06 & \\
\hline
\end{tabular}

1 


\section{Table 2 (on next page)}

Model errors (validation run $\mathrm{Q}=10.5 \mathrm{~m}^{3} / \mathrm{s}$ )

Q -discharge, E - mean error in river reach, index $\mathrm{m}$ - model result, $\mathrm{v}$ - velocity, $\mathrm{H}$ - water level 


\begin{tabular}{|c|c|c|c|c|c|c|c|c|c|c|}
\hline Reach & $\mathrm{km}$ & $\begin{array}{c}\mathrm{Q} \\
{\left[\mathrm{m}^{3} / \mathrm{s}\right]}\end{array}$ & $\begin{array}{c}\mathrm{Q}_{\mathrm{m}} \\
{\left[\mathrm{m}^{3} / \mathrm{s}\right]}\end{array}$ & $\begin{array}{c}\mathrm{E}_{\mathrm{Q}} \\
{\left[\mathrm{m}^{3} / \mathrm{s}\right]}\end{array}$ & $\begin{array}{c}\mathrm{H} \\
{[\mathrm{m}} \\
\text { a.s.1] }\end{array}$ & $\begin{array}{c}\mathrm{H}_{\mathrm{m}} \\
{[\mathrm{m}} \\
\text { a.s.1] }\end{array}$ & $\begin{array}{c}E_{H} \\
{[\mathrm{~m}]}\end{array}$ & $\begin{array}{c}\mathrm{V} \\
{[\mathrm{m} / \mathrm{s}]}\end{array}$ & $\begin{array}{c}\mathrm{V}_{\mathrm{m}} \\
{[\mathrm{m} / \mathrm{s}]}\end{array}$ & $\begin{array}{c}\mathrm{E}_{\mathrm{v}} \\
{[\mathrm{m} / \mathrm{s}]}\end{array}$ \\
\hline \multirow{3}{*}{ ND } & $0+000$ & \multirow{3}{*}{10.5} & \multirow{3}{*}{10.5} & \multirow{3}{*}{0} & 115.45 & 115.42 & \multirow{3}{*}{0.04} & 0.47 & 0.49 & \multirow{3}{*}{0.03} \\
\hline & $0+840$ & & & & 115.64 & 115.68 & & 0.44 & 0.47 & \\
\hline & $1+365$ & & & & 115.78 & 115.82 & & 0.41 & 0.45 & \\
\hline \multirow{3}{*}{ NR } & $2+920$ & \multirow{3}{*}{9.55} & \multirow{3}{*}{9.64} & \multirow{3}{*}{0.08} & 116.10 & 116.07 & \multirow{3}{*}{0.07} & 0.40 & 0.42 & \multirow{3}{*}{0.01} \\
\hline & $4+460$ & & & & 116.36 & 116.30 & & 0.41 & 0.41 & \\
\hline & $5+050$ & & & & 116.49 & 116.38 & & 0.39 & 0.38 & \\
\hline \multirow{3}{*}{ NL } & $1+180$ & \multirow{3}{*}{0.95} & \multirow{3}{*}{0.87} & \multirow{3}{*}{0.09} & 115.92 & 115.95 & \multirow{3}{*}{0.04} & 0.07 & 0.06 & \multirow{3}{*}{0.01} \\
\hline & $2+700$ & & & & 116.12 & 116.14 & & 0.10 & 0.09 & \\
\hline & $4+090$ & & & & 116.34 & 116.28 & & 0.09 & 0.08 & \\
\hline
\end{tabular}

1

2 